\title{
Cultural Influences on Environmental Consciousness and Green Environmental Behavior
}

\author{
Bashar S. Gammoh ${ }^{1}$, Sam C. Okoroafo ${ }^{1}$ \& Anthony C. Koh ${ }^{1}$ \\ ${ }^{1}$ College of Business and Innovation, University of Toledo, Toledo, Ohio, USA \\ Correspondence: Bashar S. Gammoh, College of Business and Innovation, University of Toledo, Toledo, OH \\ 43606, USA. E-mail: bashar.gammoh@utoledo.edu
}

Received: December 4, 2018 Accepted: December 30, 2018 Online Published: January 11, 2019

doi:10.5539/ijms.v11n1p20 URL: https://doi.org/10.5539/ijms.v11n1p20

\begin{abstract}
This paper focuses on investigating the relationship between culture and green attitudes and environmental behavior across two countries representing societies with different cultural norms. The paper presents a theoretical model suggesting that individual level cultural differences influence consumer's environmental consciousness which then influence their green consumerism and active ecological Behaviors'. Data was collected using survey research from two countries representing societies with different cultural norms-the United States and India. SmartPLS was used to assess the quality of the measurement model and test the proposed research hypotheses. Although the United States is a society that is generally driven by individualism and mastery orientation, study results indicate that at the individual level people attitudes and behaviors might be influenced by different orientations depending on the consumption situation. Overall, study findings highlight the value in understanding the influence of cultural factors at the individual level and not just at the country level.
\end{abstract}

Keywords: cultural influences, individualism/collectivism, mastery/harmony, environmental concerns, green behavior

\section{Introduction}

Environmental degradation is of increasing concern around the world (Ritter et. al., 2015; Fraj-Andres, 2008; Laroche et al., 2002). Consequently, environmental concern is important from both business and consumer perspectives (Cho et al., 2013; Schultz, 2002). According to Milfont et al. (2006) environmental concern (EC) reflect the emotions, or worry, linked to individuals' beliefs about environmental problems. However, not everyone is pursuing pro-environmental (green) Behavior. People make decisions based on a multitude of criteria, some of which are culturally-based (Cho et al., 2013), and some are not (Haniffa et al., 2000; Milfont et al., 2006). Milfont et al. (2006) noted the impact of culture stating that it can influence the environmental attitudes people will likely develop and subsequent green behavior people will likely take. For example, individuals may base their actions on individualistic, collectivistic, or a combination of both influences without consciously being aware of this fact (Hofstede, 1984; Cavusgil et al., 2017; McCarty et al., 2001).

This research contributes to the existing research by examining the influence of culture on environmental concerns and subsequent green environmental behavior across two countries representing societies with different cultural norms-India and the United States. India was chosen because it is representative of a collectivistic society, where there is a large emphasis on friendship and people to act jointly in favor of the group. In such societies conflict avoidance and harmony are observed with a contextual approach traditionally favored for the majority of tasks. The United States was selected since people in this mastery-oriented society tend to be more individualistic with cultural influences pressing them to think more independently, not worrying as much about group pressure. The premise of our model reflects the fact that behavior stems from environmental concern which is directly influenced by culture. More specifically, we generate hypotheses regarding the influence of cultural differences measured at the individual level (i.e., individualism/collectivism and mastery/harmony) on consumer's environmental concerns and green environmental behavior. Data was collected via survey research from the United States and India. SmartPLS was used to assess the quality of the measurement model and test the proposed research hypotheses.

The remaining of the paper is organized as follows. First, we provide some theoretical background for the role of culture in influencing environmental concerns and green Behavior and develop our research propositions. Next, 
we present the research methodology, data collection and analysis procedures, and discuss study results. Finally, we discuss study implications, limitations, and offer some directions for future research.

\section{Literature Review}

Hofstede (1991) describes the concept of culture as a type of mental programming that people start acquiring from the day we are born, which continues throughout our lives. Schultz (2002) reflected on cultural values as being ideals and goals looked upon as guiding principles. His definition is as follows (2001): "The collective programming of the mind that distinguishes the members of one group or category of people, from another". Kahn (1979) posited that nations have specific cultures that are somewhat difficult to change to any great extent, even though they can be modified over time. Even though the term culture is generally relegated to societies, it can also be examined at an array of different human groupings (e.g., an organization, an ethnic group, or a family) or examined at the individual level (McCarty et al., 2001).

Cultural models can offer insight into consumer attitude regarding environmental issues (Hofstede, 1991). Haniffa et al. (2000) stated that differences can take place within a culture based on norms. Ignatow (2006) found that national culture can have substantial effects on environmental concern. Hofstede (1984) and Tompenaars (1998) argue that culture exert a very strong influence on people behavior. Culture affects not only the inquisitiveness of the members of a society, but also their rate of tolerance change, discovery and innovation (Wallace, 2001, p. 34). Consequently, people with the same goals in different cultures will not act the same to achieve their goals. Schultz (2002) noted that environmental concern can be driven by very different reasons for different people. This study focuses on Hofstede's "individualism/collectivism" dimension and Schwartz (1999) "mastery/harmony" dimension.

\subsection{Individualism/Collectivism}

This dimension pertains to the relationship an individual express towards other members of society. It captures whether or not people are more focused on their society, while sublimating their own personal needs, and goals for advancement. The range of ties amongst society's members varies. At one end there are loose ties, where everyone needs to look after their own-self-interests, with little concern for the group, reflecting a more individualistic view of life. Collectivistic individuals are at the opposite extreme where personal ties are strong, and people tend to be less concerned about their own self-interests, and more about the group. In such societies, the group ideology tends to predominate.

\subsection{Mastery/Harmony}

This dimension reflects how an individual prioritizes success and failure. Their views regarding what constitutes success and the related risks taken to achieve it are dominant, as well as how to approach others in the context of a social relationship. Mastery reflects a cultural focus on advancement through the process of self-assertion, ambition, and the willingness to gamble for success. In this type of person, there is a large emphasis on succeeding in life. Harmony refers to a cultural approach in which the individual seeks unity with nature as evidenced with environmental protection, and finding beauty in one' surroundings

\subsection{Study Context: India vs. USA}

Different cultural lifestyles reflect environmental behavior in various ways (Thogersen et. al., 2015; Cho et. al., 2013). Hofstede $(1984,2001)$ offered support for this with information for cultural influences. In India the cultural influences are collectivistic and reflect on harmony. In this nation people tend to be more influenced by social norms, display a willingness to share resources, and focus on long-term goals to benefit the good of the group (McCarty et al., 2001). This society also exhibits acceptance of a power level stratification with a tendency to avoid confrontation with leaders. Similar, hedonic goals were discussed by Lindenberg (2007). Schultz (2002) reflected on his findings about collectivistic cultures concluding such cultures are more likely to engage in pro-environmental behavior, noting that even within cultures there are differences in respondents' attitudes.

Conversely, in the United States, cultural influences are individualistic and possess mastery values. People in this country tend to have the following tendencies: loose ties with other people beyond the nuclear family, seek short-term benefits, and reflect equal distribution of power and ease of confrontation. Schwartz (1999) is consistent with these viewpoints, in reflecting on mastery/harmony perspective. Milfont et al. (2006) discussed this and posited that Swartz's culture value dimension of harmony/mastery better reflects environmental concern. According to Schultz (2002), people in the U.S. focus more on local issues, with a greater likelihood of short-term accomplishment. 


\section{Research Hypotheses}

Societal roles tend to indicate how an individual perceives themselves within a group. Culture plays a large role in this and can be viewed by reflecting on the norms of the society. People generally often base their actions either on Individualistic or collectivistic thinking without consciously knowing it. Such thinking relates to societal roles (Hofstede, 1984; Cavusgil et al., 2008). Different lifestyles may relate to positive environmental Behavior in different ways. For example, individualistic people tend to value the importance of their own specific needs and beliefs-seeking short-term benefits (e.g., saving money). Granzin et al. (1991) reflected on the fact that there may be a cost/benefit thought process taking place in the consumer's mind, which is referenced as a hedonic goal by Lindenberg (2007). Correspondingly, there is a good likelihood for mastering the issue, such as would be exhibited by an increased tendency to debate issues with leaders.

On the other hand, collectivistic individuals tend to be more influenced by group thought processes with a focus on harmony. For example, they show a willingness to share scarce resources, avoid conflicts with leaders, and focus on long-term goals to benefit the good of the group (McCarty et al., 2001) (e.g., benefit the community, protect nature). Social norms can act as a context for the adoption of other environmental Behaviors (Berger, 1997). Not everyone is sufficiently self-motivated to become involved in pro-environmental Behavior. Both proper distribution logistics, as well as pertinent information is important to drive consumers to get involved in pro-environmental behavior (Tilikidou, 2008). In a collectivist society, such as India, an external control effect could occur due to the propensity of individuals avoiding conflict (Hofstede, 1984). Fraj-Andres et al. (2006) found a significant link between individuals with enterprising spirits who possess the belief that new challenges offer the best potential for fulfillment. In such scenarios, individualistic society cultural influences would prevail. However, contradictions can occur because the authors found no significant link between those who liked to be in charge and environmental Behavior. This means that simply because someone who is influenced by an Individualistic culture, or is in an upper category (level) in a collectivistic one, may not necessarily try to manage environmental activities. In the Indian culture, one would most likely find that many questions exhibited in the general population would be deferred to their supervisor, or one of power and respect.

In summary, existing research suggest similar goals regarding green environmental behavior across the USA and India. However, the two countries represent societies with two different cultures. Therefore, even though the goals would be the same, the activities and pathways for attaining them may be culturally influenced and quite different. We build upon the insights gained from these previous studies in order to examine the influence individualism/collectivism and mastery/harmony on individual's environmental consciousness and its effect on subsequent green consumerism and active ecological Behaviors across the USA and India. As such, we predict that the influence of cultural factors on environmental consciousness will vary depending on the country (i.e., USA \& India). Consistent with this notion, we hypothesize the following:

Hypothesis 1: a) Individualism and b) Mastery will be related to environmental consciousness in the United States but not in India.

Hypothesis 2: a) Collectivism and b) Harmony will be related to environmental consciousness in India but not in the United States.

Hypothesis 3: Environmental consciousness is related to both active ecological Behavior and green consumer Behavior in both the United States and India.

\section{Methodology}

Study participants in the United States $\left(\mathrm{n}_{\mathrm{U} . \mathrm{S}}=202, \mathrm{M}_{\mathrm{age}}=35, \mathrm{SD}_{\mathrm{age}}=12.77\right.$, Male $\left.=50.5 \%\right)$ and India $\left(\mathrm{n}_{\text {India }}=145\right.$, $\mathrm{M}_{\mathrm{age}}=29, \mathrm{SD}_{\mathrm{age}}=8.89$, Male $=58.6 \%$ ) completed a questionnaire that contained demographic characteristics, study measures, and some related control variables. Students from two universities located in major cities in the Mid-west United Sates and South India helped in recruiting appropriate subjects for the study in exchange for extra credit. Similar studies (e.g., Vicente-Molina et. al., 2013; Dutta et. al., 2008) have used Indian and US students to investigate environmental Behavior (Montgomery \& Stone 2009).

Existing multi-item measures were adopted from literature to measure study constructs. Collectivism (COL) and individualism (IND) were measured using three-item and two-item scales, respectively, adopted from McCarty and Shrum (2001). Scales to measure harmony (HAR) (three-items) and mastery (MAS) (five-items) were adopted from Schwartz (1999). A ten-item scale adopted from Alsmadi (2007) was used to measure Environmental consciousness (EC). Finally, two constructs were measured to capture green environmental Behavior. The first is a four-item scale adopted from Karfiatis, Horardas and Pantis (2004) to measure active ecological Behavior (AEB) and the second is a twelfth-item scale adopted from Alsmadi (2007) to capture green consumerism Behavior (GCB) 
(see Appendix for study measures).

Table 1 provides summary statistics and correlations for study variables across the two samples. Means and level of correlation among study variables across the United States and Indian samples were consistent with our conceptualization and previous research. For example, as expected, Table 1 shows that subjects from India reported significantly higher levels of Collectivism $\left(\mathrm{M}_{\text {India }}=5.75>\mathrm{M}_{\mathrm{USA}}=5.26, t_{(d f 345)}=-6.57, p=.000\right)$ and Harmony $\left(\mathrm{M}_{\text {India }}=5.79>\mathrm{M}_{\mathrm{USA}}=4.75, t_{(d f 345)}=-8.31, p=.000\right)$ relative to subjects from the United States. Whereas subjects from the United States reported higher levels of individualism $\left(\mathrm{M}_{\mathrm{USA}}=5.22>\mathrm{M}_{\text {India }}=4.71, t_{(d f 345)}=6.33, p=.000\right)$ and Mastery $\left(\mathrm{M}_{\mathrm{USA}}=5.77>\mathrm{M}_{\text {India }}=5.34, t_{(d f 345)}=5.19, p=.000\right)$ relative to subjects from India. Also, it's worth noting that Indian subjects reported higher levels on EC, GCB, and AEB. Previous studies support this pattern of findings; consumers in developing countries (i.e., India) tend to show higher levels of environmental consciences and environmental intentions (e.g., Schultz 2002).

SmartPLS (Ringle et al., 2005) was used to assess the measurement model and test the proposed hypotheses for each sample (Anderson \& Gerbing, 1988; Joreskog \& Sorbom, 1984). Indicator reliability for items comprising each construct, overall construct composite reliability, average variance extracted, and discriminant validity across the two samples show acceptable ranges (see Table 1) indicating that our measurement model was adequate for both samples (Hair et al., 2014).

Table 1. Descriptive statistics and correlations

U.S. Sample $(\mathrm{n}=202)$

\begin{tabular}{llllllllll}
\hline & Mean & S.D. & COL & IND & HAR & MAS & EC & GCB & AEB \\
\hline COL & 5.26 & 0.75 & 1.00 & & & & & & \\
IND & 5.22 & 0.68 & 0.052 & 1.00 & & & & & \\
HAR & 4.75 & 1.34 & $0.153^{\mathrm{a}}$ & 0.113 & 1.00 & & & & \\
MAS & 5.77 & 0.70 & $0.064^{\mathrm{a}}$ & $0.180^{\mathrm{a}}$ & $0.341^{\mathrm{b}}$ & 1.00 & & & \\
EC & 5.35 & 1.08 & $0.278^{\mathrm{b}}$ & -0.030 & $0.549^{\mathrm{b}}$ & $0.235^{\mathrm{b}}$ & 1.00 & & \\
GCB & 3.77 & 1.47 & $0.139^{\mathrm{a}}$ & -0.074 & $0.535^{\mathrm{b}}$ & 0.089 & $0.598^{\mathrm{b}}$ & 1.00 & \\
AEB & 3.78 & 1.35 & $0.156^{\mathrm{a}}$ & -0.105 & $0.481^{\mathrm{b}}$ & 0.098 & $0.504^{\mathrm{b}}$ & $0.709^{\mathrm{b}}$ & 1.00 \\
AVE & & & .613 & .532 & .712 & .558 & .628 & .733 & .776 \\
CR & & & .825 & .813 & .879 & .826 & .944 & .970 & .912 \\
\hline
\end{tabular}

India Sample $(\mathrm{n}=145)$

\begin{tabular}{llllllllll}
\hline & Mean & S.D. & COL & IND & HAR & MAS & EC & GCB & AEB \\
\hline COL & 5.75 & 0.59 & 1.00 & & & & & & \\
IND & 4.71 & 0.82 & -0.073 & 1.00 & & & & & \\
HAR & 5.79 & 0.81 & $0.181^{\mathrm{a}}$ & 0.051 & 1.00 & & & & \\
MAS & 5.34 & 0.80 & $0.184^{\mathrm{a}}$ & 0.043 & $0.355^{\mathrm{b}}$ & 1.00 & & & \\
EC & 5.86 & 0.81 & $0.337^{\mathrm{b}}$ & -0.052 & $0.417^{\mathrm{b}}$ & $0.195^{\mathrm{a}}$ & 1.00 & & \\
GCB & 4.89 & 1.02 & $0.228^{\mathrm{b}}$ & 0.081 & $0.336^{\mathrm{b}}$ & 0.140 & $0.361^{\mathrm{b}}$ & 1.00 & \\
AEB & 4.80 & 1.22 & $0.151^{\mathrm{b}}$ & 0.012 & $0.353^{\mathrm{b}}$ & 0.073 & $0.401^{\mathrm{b}}$ & $0.588^{\mathrm{b}}$ & 1.00 \\
AVE & & & .516 & .572 & .606 & .523 & .537 & .559 & .632 \\
CR & & & .736 & .795 & .809 & .789 & .920 & .938 & .870 \\
\hline
\end{tabular}

Note. S.D.=standard deviation.

$\mathrm{AVE}=$ average variance extracted.

$\mathrm{CR}=$ composite reliability.

Entries below the diagonal of the correlation matrix are construct correlations.

${ }^{a}$ Correlation is significant at the 0.05 level.

${ }^{\mathrm{b}}$ Correlation is significant at the 0.01 level.

$\mathrm{COL}=$ Collectivism; IND=Individualism; HAR=Harmony; MAS=Mastery; $\mathrm{EC}=$ Environmental Consciousness; $\mathrm{GCB}=\mathrm{Green}$ Consumer Behavior; $\mathrm{AEB}=$ Active Ecological Behavior.

\section{Hypotheses Testing}

In $\mathrm{P}_{1} \mathrm{a}$ and $\mathrm{b}$ we proposed that both Individualism and Mastery will be related to environmental consciousness in the United States but not in India. As shown in Figure 1 and Table 2, our results indicate that the paths between Individualism and Environmental Consciousness were not significant in both samples (USA: $\beta=-.028, t=0.230$; India: $\beta=-.095, t=0.545)$. Similarly, paths between Mastery and Environmental Consciousness were not significant 
in both samples (USA: $\beta=.066, t=0.811$; India: $\beta=.152, t=1.266$ ). As such, we find partial support for proposition 1 $a$ and $b$. Both Individualism and Mastery had no significant relationship with environmental consciousness in both samples. $\mathrm{P}_{2} \mathrm{a}$ and $\mathrm{b}$ proposed that both Collectivism and Harmony will be related to environmental consciousness in India but not in the United States. Collectivism-Environmental Consciousness path was significant in both samples (USA: $\beta=.216, p<.01$; India: $\beta=.215, p<.05$ ). Harmony-Environmental Consciousness path was also significant in both samples (USA: $\beta=.603$, $p<.01$; India: $\beta=.316, p<.01$ ). As such, we find partial support for proposition $2 \mathrm{a}$ and $\mathrm{b}$. Contrary to our expectations both Collectivism and Harmony had a significant relationship with Environmental Consciousness in both samples. Overall, the model accounted for a substantial amount of variance in Environmental Consciousness for both samples $\left(\mathrm{R}_{\text {United States }}^{2}=.382 ; \mathrm{R}_{\text {India }}^{2}=.304\right)$.

The model was supportive of Environmental Consciousness (EC) relationship with both Green Consumerism Behavior (GCB) and Active Ecological Behavior (AEB) in both samples. EC-GCB paths (USA: $\beta=.810, p<.01$; India: $\beta=.391, p<.01$ ) and EC-AEB paths (USA: $\beta=.533$, $p<.01$; India: $\beta=.439, p<.01$ ) were significant for both samples. This supports P3. Furthermore, EC accounted for a considerable amount of variance in both Behavioral outcomes and in both samples (GCB: $\mathrm{R}_{\text {United States }}^{2}=.372, \mathrm{R}_{\text {India }}^{2}=.153$; AEB: $\left.\mathrm{R}_{\text {United States }}^{2}=.284, \mathrm{R}_{\text {India }}^{2}=.192\right)$. Table 2 summarizes this results section. We also incorporated these results into the model from Figure 1.

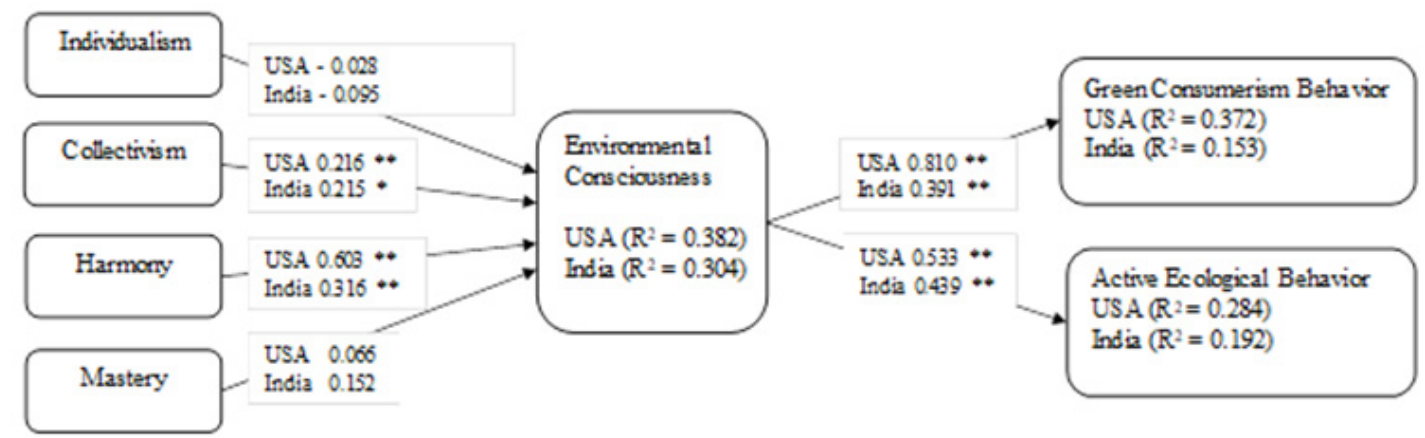

Figure 1. Research model and results

Note. Standardized $\beta$ coefficients are reported.

$$
\begin{aligned}
& \mathrm{n}_{\text {U. } . ~}=202 \& \mathrm{n}_{\text {India }}=145 . \\
& \aleph_{\mathrm{p}} \leq 0.01 . \\
& \aleph_{\mathrm{p} \leq 0.05 .}
\end{aligned}
$$

Table 2. Model results

Note. $* \mathrm{p}<.05 ; *$ p $<.01$.

\begin{tabular}{lllll}
\hline \multirow{2}{*}{ Path } & \multicolumn{2}{l}{ U.S. Sample } & \multicolumn{2}{l}{ Indian Sample } \\
\cline { 2 - 5 } & b-value & t-value & b-value & t-value \\
\hline IND $\rightarrow$ EC & -0.028 & 0.230 & -0.095 & 0.545 \\
COL $\rightarrow$ EC & 0.216 & $2.747 * *$ & 0.215 & $2.152 *$ \\
HAR $\rightarrow$ EC & 0.603 & $6.940 * *$ & 0.316 & $2.720^{* *}$ \\
MAS $\rightarrow$ EC & 0.066 & 0.811 & 0.152 & 1.266 \\
EC $\rightarrow$ GCB & 0.810 & $11.419 * *$ & 0.391 & $3.626 * *$ \\
EC $\rightarrow$ AEB & 0.533 & $8.517 * *$ & 0.439 & $6.579 * *$ \\
\hline
\end{tabular}

$\mathrm{COL}=$ Collectivism; IND=Individualism; HAR=Harmony; MAS=Mastery; $\mathrm{EC}=$ Environmental Consciousness; $\mathrm{GCB}=\mathrm{Green}$ Consumer Behavior; $\mathrm{AEB}=$ Active Ecological Behavior.

\section{Discussion}

Recent literature has given increasing attention to consumer's perceptions and reactions to environmental issues and green environmental behavior. This research focused on highlighting the role of some cultural variables in influencing such perceptions and behaviors. More specifically, we examined the difference in the influence of these cultural values across two somewhat different cultures - the United States and India.

As expected, individualism was not significantly related to environmental consciousness in India. However, and contrary to our proposition, individualism was also not significantly related to environmental consciousness in the United States. Furthermore, as proposed, collectivism significantly influenced environmental consciousness in 
India. However, contrary to our expectations, collectivism was also a significant predictor of environmental consciousness for our sample from the United States. In what follows we offer some potential explanation for our results. At the macro-cultural level, cultures are considered as being either collectivistic or individualistic in their orientations (Hofstede, 1983; Triandis, 1996). In general, the United States is considered an individualistic society with less collectivist impact on people Behavior. However, when examined at the individual level, both dimensions exist within and an individual can display both tendencies across different situations (Triandis, 1996). Findings in this paper show that at the individual level for environmental related perceptions and behaviors, collectivism is strongly related to green consciousness for the US sample. Our results for the Indian sample support our propositions. Results show strong positive influence for collectivism on environmental consciousness while the influence of individualism was not significant.

Results indicate that mastery had no significant influence on environmental consciousness in both countries while harmony had a significant influence on environmental consciousness in both countries. Such results suggest that while at the macro level the United States is a society that is driven more by mastery orientation, at the individual level people might be driven by different orientations depending on the decision and/or consumption context. For example, within a career or work context individuals might be more likely to be driven by a mastery orientation, while they might be driven more by harmony orientation within other contexts (such as environmental issues). Such issues need to be examined more directly in future research efforts. Finally, study findings indicate that environmental consciousness exerts a positive and significant influence on both green consumerism Behavior and active ecological Behavior. This finding is consistent with existing literature regarding the important of environmental attitudes and perceptions in driving environmental behavior.

\section{Conclusions}

Our results provide important theoretical and practical implications. Theoretically, while most existing research focused on the influence of these cultural factors on environmental attitudes and behaviors at the country level, we investigated such issues at the individual consumer level. Overall, we highlight the value in understanding the influence of cultural factors at the individual level and not just at the country level. More research in the field argues for the examination of cultural influences at the micro individual level as well as the macro country level. Our findings support such arguments. In terms of practical implications, our findings should help marketers and policy makers. Our research provides a look at some important cultural variables that influence environmental consciousness and green environmental behavior. Given our results global brand managers should focus their brand appeals to the collectivity and harmony with the environment despite what the existing literature might suggest regarding the United States culture in general. It seems that while at the overall society level the United States might be categorized as an individualistic rather than collectivistic culture. At the individual level and considering attitudes and behaviors toward green environmental issues our results shows that collectivism and sense of community was still positively and strongly related to environmental consciousness within the United States and India. As such, marketers trying to reach consumers in the United States and India markets could develop marketing strategies and messages that appeal to the collectivity and harmony orientation of consumers. For example, they can promote their green products by highlighting its benefits to the entire society and the environment. Overall, our findings highlight the importance of examining cultural factors in designing environmental campaigns and green messaging efforts across international markets. Global marketing managers should pay attention to consumer's levels of individualism, collectivism, harmony and mastery in their positioning and communication strategies.

The generalizability of our findings might be limited in terms of the selected countries. Future research is encouraged to re-examine our model across other countries. Furthermore, future research should explore the potential influence of other factors that might influence consumer environmental attitudes and behaviors. For example, the issues of the availability of resources and exposure to environmental issues might influence green environmental behavior beyond the influence of cultural differences. Furthermore, existing research suggest that perceived quality of green products and consumer trust in green environmental claims might play a key role in influencing their actual green environmental behavior.

\section{References}

Anderson, J. C., \& Gerbing, D. (1998). Structural equation modeling in practice: A review and recommended two-step approach. Psychological Bulletin, 103(3), 411-423. https://doi.org/10.1037/0033-2909.103.3.411

Berger, I. E. (1997). The demographics of recycling and the structure of environmental Behavior. Environment and Behavior, 29, 515-531. https://doi.org/10.1177/001391659702900404 
Cavusgil, S. T., Knight, G., \& Riesenberger, J. R. (2017). International Business-The New Realities (4th ed.). Upper Saddle River, NJ: Prentice Hall.

Cho, Y. N., Thyroff, A., Rapert, M. I., Park, S. Y., \& Lee, H. L. (2013). To be or not to be Green: Exploring Individualism and Collectivism as Antecedents of Environmental Behavior. Journal of Business Research, 66, 1052-1059. https://doi.org/10.1016/j.jbusres.2012.08.020

Dubey, P. (2008). Recycling business: Cases of strategic choice for green marketing in Japan. IIMB Management Review, September, 263-278.

Dutta, K., Umashankar, V., Choi, G., \& Parsa, H. G. (2008). A Comparative Study of Consumer' Green Orientation in India and the United States: A Study from the Restaurant Industry. Journal of Foodservice Business Research, 11(3), 269-285. https://doi.org/10.1080/15378020802316570

Fraj, E., \& Martinez, E. (2008). Ecological consumer Behavior: An empirical analysis. International Journal of Consumer Studies, 31(1), 26-33.

Fraj-Andres, E., \& Martinez-Salinas, E. (2006). Environmental values and lifestyles as determining factors of ecological consumer Behavior: An empirical analysis. Journal of Consumer Marketing, 23(3), 133-144. https://doi.org/10.1108/07363760610663295

Fraj-Andres, E., \& Martinez-Salinas, E. (2006). Impact of environmental knowledge on ecological consumer Behavior: An empirical analysis. Journal of International Consumer Marketing, 19(3), 73-102. https://doi.org/10.1300/J046v19n03_05

Granzin, K. L., \& Olsen, J. E. (1991). Characterizing participants in activities protecting the environment: A focus on donating, recycling, and conservation Behaviors. Journal of Public Policy and Marketing, 10(2), $1-27$.

Hair, J. F., Hult, T. M., Ringle, C. M., \& Sarstedt, M. (2014). A Primer on Partial Least Squares Stuctural Equation Modeling (PLS-SEM). SAGE Publishing.

Haniffa, R., \& Cooke, T. (2000). Culture, Corporate Governance and Disclosure in Malaysian Corporations. The Asian AAA World Conference in Singapore, 28-30.

Hofstede, G. (1983). The Cultural Relativity of Organizational Practices and Theories. Journal of International Business Studies, 75-89. https://doi.org/10.1057/palgrave.jibs.8490867

Hofstede, G. (1984). Culture's Consequences: International Differences in Work-Related Values. Thousand Oaks, CA: Sage Publ.

Hofstede, G. (2001). Culture's Consequences: Comparing Values Behaviors, Institutions, and Organizations across Nations (2nd ed.). Thousand Oaks, CA: Sage Publ.

Hofstede, G., \& Bond, M. (1991). The Confucius Connection: From Cultural Roots to Economic Growth, Organizational Dynamics, 16(4), 4-21.

Ignatow, G. (2006). Cultural models of nature and society-Reconsidering environmental attitudes and concern. Environment and Behavior, 38(4), 441-461. https://doi.org/10.1177/0013916505280791

Joreskog, K., \& Sorbom, D. (1984). LISREL VI: Analysis of Linear Structural.

Kahn, H. (1979). World economic development: 1979 and beyond. Boulder CO: Westview Press.

Laroche, M., Bergeron, J., Tomiuk, M., \& Barbaro-Forieo, G. (2002). Cultural differences in environmental knowledge, attitudes, and Behaviors of Canadian consumers. Canadian Journal of Administrative Services, 19(3), 267-283. https://doi.org/10.1111/j.1936-4490.2002.tb00272.x

Lindenberg, S., \& Steg, L., G. (2007). Normative, gain, and hedonic goal frames guiding environmental Behavior. Journal of Social Issues, 6(1), 117-137. https://doi.org/10.1111/j.1540-4560.2007.00499.x

McCarty, J. A., \& Shrum, L. J. (2001). The influence of individualism, collectivism, and locus of control on environmental beliefs and Behavior. Journal of Public Policy and Marketing, 20(1), 93-104. https://doi.org/10.1509/jppm.20.1.93.17291

Milfont, T. L., Duckitt, J., \& Cameron, L. D. (2006). A cross-cultural study of environmental motive concerns and their implications for pro-environmental Behavior. Environment and Behavior, 38(6), 745-767. https://doi.org/10.1177/0013916505285933 
Montgomery, C., \& Stone, G. (2009). Revisiting Consumer Environmental Responsibility: Cross-Cultural Analysis and Comparison of Consumer Ecological Opinions and Behavior. International Journal of Management \& Marketing Research, 2(1), 35-58.

Pantis, J. D., Konstantinos, J. K., \& Tasos, H. (2004). Determinants of Environmental Behavior in Societies in Transition: Evidence from Five European Countries. Population and Environment, 25(6), 563-584.

Ringle, C. M., Wende, S., \& Will, S. (Eds.). (2005). SmartPLS 2.0 (M3) (Beta). Hamburg, Germany: University of Hamburg. Retrieved from http://www.smartpls.de

Ritter, A., Borchardt, M., Vaccaro, G., Pereira, G., \& Almeida, F. (2015). Motivations for Promoting the Consumption of Green Products in an Emerging Country: Exploring Attitudes of Brazilian Consumers. Journal of Cleaner Production, 106, 507-520. https://doi.org/10.1016/j.jclepro.2014.11.066

Schultz, W. P. (2002). Environmental attitudes and Behaviors across cultures. Online Readings in Psychology and Culture, Unit 8, Chapter 4, 1-8. https://doi.org/10.9707/2307-0919.1070

Schwartz, H. S. (1992). Universals in the Content and Structures of Values: Theoretical Advances and Empirical Tests in 20 Countries, In M. Zanna (Eds.), Advances in Experimental Psychology (pp. 1-65). Orlando, FL: Academic Press. https://doi.org/10.1016/S0065-2601(08)60281-6

Schwartz, H. S. (1999). A theory of cultural values and some implications for work. Applied Psychology: An International Review, 48(1), 23-47. https://doi.org/10.1111/j.1464-0597.1999.tb00047.x

Thogersen, J., De Barcellos, M., Perin, M., \& Zhou, Y. (2016). Consumer Buying Motive and Attitudes Towards Organic Food in Two Emerging markets. International Marketing Review, 32(3/4), 389-413.

Tilikidou, I., \& Delistavrou, A. (2008). Types and influential factors of consumers' non-purchasing ecological Behaviors. Business Strategy and the Environment, 18, 61-76. https://doi.org/10.1002/bse.500

Triandis, C. (1996). The psychological Measurement of Cultural Syndromes. American Psychological Association, 52(4), 407-415. https://doi.org/10.1037/0003-066X.51.4.407

Vicente-Molina, M., Fernandez-Sainz, A., \& Izagirre-Olaizola, J. (2013). Environmental Knowledge and other Variables affecting Pro-environmental Behavior: Comparison of University Students from Emerging and Advanced Countries. Journal of Cleaner Production, 13(61), 130-138. https://doi.org/10.1016/j.jclepro.2013.05.015

Wallace, A. F. C. (1970). Culture and Personality. New York: Random House.

\section{Appendix}

\section{Measurement Items}

Individualism $^{\mathrm{a}}$ (IND) (McCarty \& Shrum, 2001)

Being unique, different from others in many respects (USA $=.757$; India $=.740$ )

Working independently from others $(\mathrm{USA}=.625$; India $=.637)$

Collectivism $^{\text {a }}$ (COL) (McCarty \& Shrum, 2001)

Working hard for the goals of the group even it doesn't result in personal recognition (USA=.695; India =.629)

Being a cooperative participant in group activities (USA=.753; India $=.892$ )

Doing what is good for most of the people in the group, even if it means that the individual will receive less (USA=.754; India $=.639$ )

Harmony $^{\mathrm{b}}$ (HAR) (Schwartz, 1999)

World of beauty (USA $=.701$; India $=.638$ )

Protect environment $(\mathrm{USA}=.894$; India $=.895)$

Unity with nature (USA $=.920$; India $=.907)$

Mastery $^{\mathrm{b}}$ (MAS) (Schwartz, 1999)

Capable (USA $=.741$; India $=.798$ )

Successful (USA=.667; India $=.618$ )

Choosing own goals (USA $=.831$; India $=.686$ ) 
Independent (USA $=.775 ;$ India $=.743$ )

Ambitious (USA=.712; India $=.615$ )

Environmental Consciousness ${ }^{\mathrm{c}}$ (EC) (Alsmadi, 2007)

I always advise others to keep the environment clean (USA=.749; India $=.879$ )

I get annoyed when someone contaminates the environment (USA $=.861$; India $=.717)$

I respect all efforts to maintain and preserve the environment (USA $=.811 ;$ India $=.749)$

I appreciate living in a healthy and clean environment (USA=.744; India $=.787$ )

I respect rules and regulations to maintain and preserve the environment (USA=.691; India $=.756$ )

I always admire those who rationalize energy consumption (USA $=.786$; India $=.740$ )

I am aware of the impact of population explosion on the environment (USA $=.865 ;$ India $=.851$ )

I realize that natural resources are scarce, thus must be used wisely (USA=.783; India $=.702$ )

I believe that man and nature have to be in harmony for survival (USA $=.803$; India $=.742$ )

I understand that the environment is for us and future generations, thus must be well maintained and preserved (USA $=.816$; India $=.765)$

Green Consumerism ${ }^{\mathrm{c}}$ (GCB) (Alsmadi, 2007)

I drive my car within speed limits to rationalize petrol consumption (USA=.690; India $=.864$ )

I avoid buying products which extensively use scarce resources (USA $=.857$; India $=.775$ )

I usually choose the products that do not come much energy (USA=.885; India $=.724$ ).

I usually buy environment-friendly products ( $\mathrm{USA}=.867$; India $=.716$ )

I may change brand loyalty for environmental reasons (USA=.872; India $=.687$ )

I always choose recyclable products (USA $=.840$; India $=.764$ )

I always advise others to buy environment-friendly products (USA $=.861$; India $=.813$ )

I always choose products with reusable packaging (USA $=.914$; India $=.727$ )

I am willing to pay extra for green products (USA $=.842$; India $=.812$ )

When I buy a product I always consider its impact on the environment (USA=.879; India $=.810$ )

I always prefer to deal with pro-environmental sellers over others (USA=.901; India $=.802)$

I am willing to spend considerable time and efforts to buy green products (USA=.864; India $=.854$ )

Active Ecological Behavior ${ }^{d}$ (AEB) (Karfiatis, Horardas \& Pantis, 2004)

Contribute time or money to an environmental or conservation group (USA $=.851 ;$ India $=.714$ )

Engage in environmental action (USA $=.887$; India $=.764$ )

Save cans, bottles or newspapers for recycling (USA=.879; India $=.821$ )

Specifically avoid using products harmful for the environment (USA=.868; India=.872)

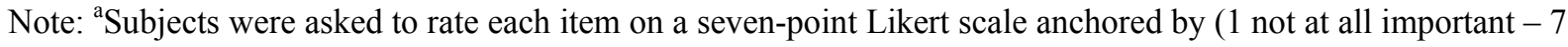
extremely important).

${ }^{\mathrm{b}}$ Subjects were asked the following: Rate the importance of each of the following items as a guiding principle in YOUR life... (1 not at all important - 7 extremely important)

${ }^{\mathrm{c}}$ Subjects were asked to indicate their level of agreement on each statement using a seven-point Likert scale anchored by (1="strongly disagree," and $7=$ "strongly agree").

${ }^{\mathrm{d}}$ Subjects were asked "How often do you do the following?", answers ranged from 1=never to 7=very often).

evalues in parentheses indicates loadings for individual items. 


\section{Copyrights}

Copyright for this article is retained by the author(s), with first publication rights granted to the journal.

This is an open-access article distributed under the terms and conditions of the Creative Commons Attribution license (http://creativecommons.org/licenses/by/4.0/). 